\title{
Design of a portable electrical and mechanical system test instrument for a certain type of aircraft
}

\author{
Feng Tian \\ School of Automation \\ Shenyang Aerospace University \\ Shenyang, China
}

\author{
Chaoqun Ma \\ School of Automation \\ Shenyang Aerospace University \\ Shenyang, China \\ machaoqun0204@126.com
}

\author{
Yongtao $\mathrm{Yu}$ \\ School of Automation \\ Shenyang Aerospace University \\ Shenyang, China
}

\begin{abstract}
In view of the test and maintenance requirements of the mechanical and electrical system of a certain type of aircraft, a kind of portable mechanical and electrical system test instrument for a certain type of aircraft is designed and realized. This test system enables to collect and display the states of mechanical and electrical subsystems of a certain type of aircraft, and can output corresponding excitation to the device interface of the aircraft electrical system measured, collect relevant data, verify the system function and detect the fault mechanical and electrical system. The system uses the Compact-DAQ modular data acquisition system of US NI company as the core, the analog and discrete acquisition board as the signal acquisition, the analog output boards and self-made discrete output module as the excitation output signal source, with the cooperation of the self-made switching matrix, to achieve the functions of the signal acquisition and real-time display, the storage and playback of data and the output of excitation signal. Test results show that the test system has the advantages of stable performance, high reliability, high testing efficiency, simple operation, and has high versatility and portability, which can meet the needs of field test.
\end{abstract}

Keywords-Mechanical and electrical system; Condition monitoring; Functional verification; Data collection; Portable

\section{INTRODUCTION}

The mechanical and electrical systems on the plane are also known as public equipment systems[1]. As an important airborne systems, aircraft electrical system, including management of mechanical and electrical, hydraulic, mechanical wheel brake, environmental control, life support, fuel, the second power, electric and other subsystems, provide power, hydraulic power, equipment cooling, engine fuel, aircraft center of gravity control, emergency start engine, fire, the pilots life support and so on for the aircraft[2]. Only when the state parameters are in normal range, can these devices work normally to ensure the normal flight of the aircraft[3]. Airborne electromechanical equipment is an important part of the aircraft, and the testing of these devices for fault detection and resolution provided an effective basis, so the test of airborne electromechanical equipment is very important[4]. The maintenance personnel of the airborne electromechanical equipment usually come from the mechanical profession, and have no deep understanding to the electrical professional knowledge. Therefore, it is necessary to design a testing system which can be used to detect the failure of the airborne electromechanical equipment in the comprehensive, accurate

This project has been supported by Liaoning Province Natural Science Foundation [20141077]. This project has been also supported by Liaoning Province Natural Science Foundation [2014024007]. and rapid detection[4]. In modern warfare, combat aircraft need efficient, reliable safeguard equipment to test and maintain. Because of the existing test equipment complicated operations, poor reliability, and low test efficiency, the new test equipment development put forward higher requirements.

\section{SYSTEM GENERAL DESIGN}

\section{A. General design}

Electromechanical system is a general term for the flight support system. It mainly includes mechanical and electrical management system, fuel subsystem, power system, power supply system, hydraulic system and environmental control system and so on. Remote Interface Unit (RIU) is a part of UMS system, which mainly completes the acquisition and output control of the system[2][5].

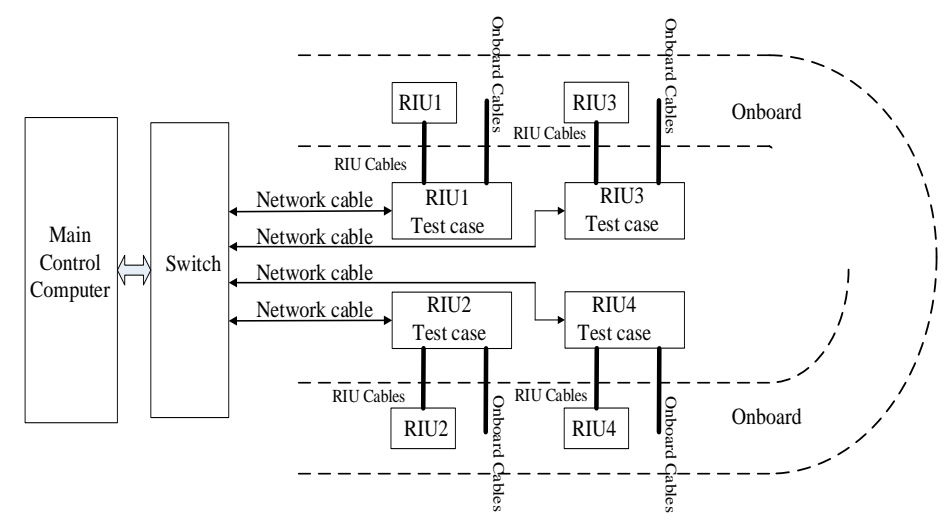

Fig 1 Overall diagram of the system

The test system designed in this paper mainly includes the main control computer and the test case. In order to meet the demand of high reliability, strong anti-interference ability, high demand for data transmission bandwidth, the system use the Ethernet network as the data transmission link between main control computer and test case[6]. The test case is connected with on-board side and RIU side through cables on-board and RIU cables. The overall diagram of the system is shown in Fig 1.The main control computer realizes the control of four RIU test case, data display and storage capabilities through the network. Each test case completes corresponding signal acquisition and transmits data to the main control computer through the network for display and storage, and receives the 
control command of the main control computer to output set excitation signal.

\section{B. Analysis of airborne electromechanical system of signals}

Different aircraft electronic systems perform specific functions to ensure the normal flight of the aircraft. With the increase of the function, the control process is more and more complex, and the interface is more and more complex, and more and more kinds of signals are involved. In the early stage, the airborne electromechanical device is controlled by a logic relay, a fluid power device, or a separate controller, a display and an alarm. In modern aircraft, it is required to connect the public equipment system to the data bus, and connect different electromechanical devices through the data bus, and access to the avionics system[7].

1) The equipment and signal of the airborne electromechanical system have the following characteristics:

2) The equipments of the system are almost all mechanical or electronic equipment.

3) The equipment and signal of the airborne electromechanical system are usually involved in energy transfer.

4) The input and output characteristics vary greatly.

5) Different machine electronic systems signal types vary greatly.

6) The number of signals is large, the type is diverse, and the processing is complex. Specific distribution is shown in TABLE I [8][9].

TABLE I. THE NUMBER OF SPECIAL SignALS CONNECTED TO AN AIRBORNE ELECTROMECHANICAL AND CONTROL UNIT

\begin{tabular}{|c|c|c|}
\hline System & $\begin{array}{c}\text { Signal } \\
\text { quantity }\end{array}$ & $\begin{array}{c}\text { Number of } \\
\text { power drives }\end{array}$ \\
\hline Engine and related systems & 141 & 33 \\
\hline Fuel measurement and management system & 206 & 36 \\
\hline Hydraulic system for shifting and braking & 146 & 13 \\
\hline $\begin{array}{c}\text { Environmental control system / cabin } \\
\text { temperature }\end{array}$ & 59 & 14 \\
\hline $\begin{array}{c}\text { Auxiliary power system } \\
\text { Other systems - monitoring and } \\
\text { detection of electronic systems }\end{array}$ & 36 & 7 \\
\hline Total & 632 & 110 \\
\hline
\end{tabular}

\section{HARDWARE Design Of The Test Instrument}

\section{A. Design of the test case}

According to the aircraft electrical equipment reliability test conditions, this test system uses the Compact-DAQ modular data acquisition system of the NI Company as the main frame, including the adapter module, the discrete data acquisition module, the analog data acquisition module, the RS-422 communication module, the analog output module, the digital output module, the power supply module. The diagram of the test case is shown in Fig 2.

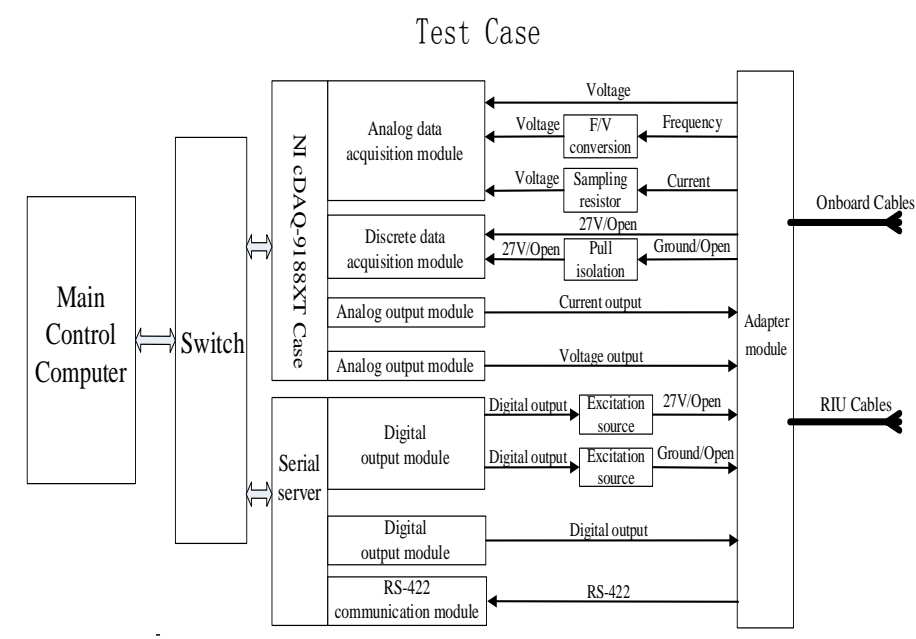

Fig 2 Diagram of the test case

B. Working principle of the system.

When using the test system, the adapter module, depending on the type of test requirements and the nature of the signal, and by controlling the corresponding relay, completes the configuration and of the corresponding test case and connection relationship among the test system, RIU, and Onboard side, and completes the configuration of signal acquisition channel and excitation output channel. According to the signal analysis of the electromechanical system, the signal types of the electromechanical system are mainly analog signal, discrete signal and frequency signal. This system uses the voltage acquisition board as the analog data acquisition board. The voltage signals can be directly collected by the voltage acquisition card. The current signals need to be converted into the corresponding voltage signal by sampling resistance, and then are acquired by the voltage acquisition card and then are converted to the corresponding current value in the software. The frequency signals need to be converted into the corresponding voltage signal by $\mathrm{F} / \mathrm{V}$ conversion and then are acquired by the voltage acquisition card. 27V/Open signal can be collected by discrete variables acquisition card. Ground/Open signal is converted to 27V/open signal through the Pull-up resistor, and then collected by discrete variables acquisition card.

\section{DESIGN OF TEST INSTRUMENT SOFTWARE}

This system realizes the data transmission between the main control computer and hardware through Ethernet. PC software running on the main control computer is designed by Microsoft software integrated development environment product Studio Visual 2010.

Software testing is divided into nine modules, including user interface module, and help module, system self-test module, excitation output module, RS-422 communication module, the adapter module, signal acquisition module, database management module, and task scheduling module. The software structure diagram is shown in Fig 3. 


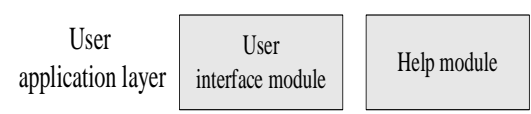

\begin{tabular}{|c|c|c|c|}
\hline $\begin{array}{c}\text { Task } \\
\text { ontrol layer }\end{array}$ & $\begin{array}{c}\text { System } \\
\text { self-test module }\end{array}$ & $\begin{array}{c}\text { Task } \\
\text { scheduling module }\end{array}$ & $\begin{array}{c}\text { Database } \\
\text { management } \\
\text { module }\end{array}$ \\
\hline
\end{tabular}

\begin{tabular}{c|c|c|c|c|}
$\begin{array}{c}\text { Hardware } \\
\text { abstraction layer }\end{array}$ & $\begin{array}{c}\text { Excitation } \\
\text { output module }\end{array}$ & $\begin{array}{c}\text { RS-422 } \\
\text { communication } \\
\text { module }\end{array}$ & $\begin{array}{c}\text { Signal } \\
\text { acquisition module }\end{array}$ & Adapter module \\
\cline { 3 - 4 } & &
\end{tabular}

Fig 3 System software structure

\section{A. User application layer}

The user interface module is primarily responsible for providing a set of user-friendly, operating style unified human-computer interface, convenient for the user to use the various functions of the software. System software server interface is shown in Fig 4, and System software client interface is shown in Fig 5.

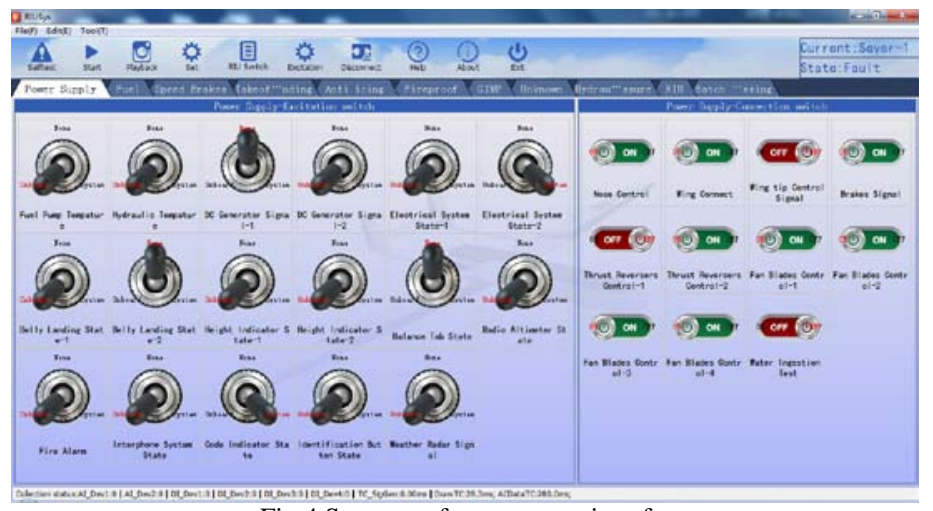

Fig 4 System software server interface

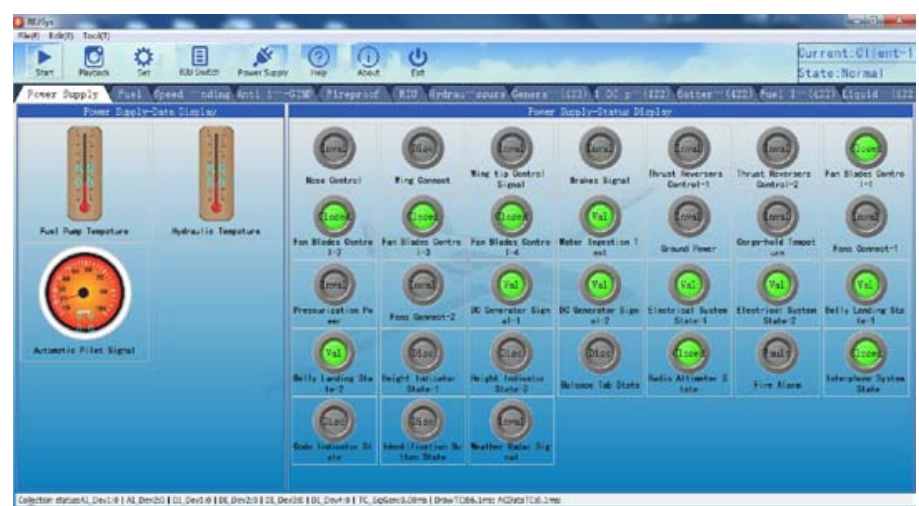

Fig 5 System software client interface

Help module provides the user with convenient information, including the instructions, operating tutorial, and solutions to common problems on the use of the test system, guiding the user to the correctly operate the software.

\section{B. Task control layer}

The system self-test module is used to complete the selftest and alarm of the system fault, and can monitor the operation of the software and hardware of the system in time, and ensure the normal operation of the system.
On the hardware, this module detects the availability of the universal part of the test case, including the controllability of the hardware acquisition components, the availability of the acquisition components and the integrity of each channel, of which the controllability and availability of the acquisition components is the main. On the software, this module, including the integrity of the data file, the integrity of the help file, the integrity of the data storage file and the integrity of the system configuration information, detects its own software running environment in order to prevent accidental deletion or loss of the key dependency. System hardware self-test flow chart is shown in Fig 6, and the system software environment self-test flow chart is shown in Fig 7.

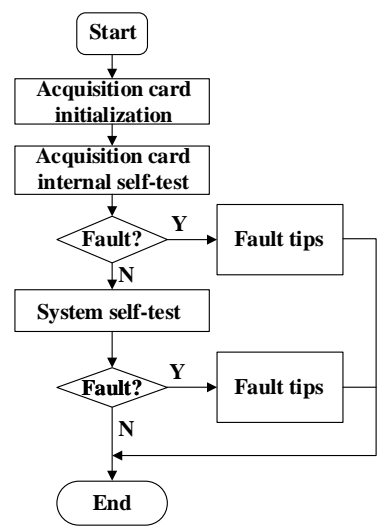

Fig 6 System hardware self-test flowchart

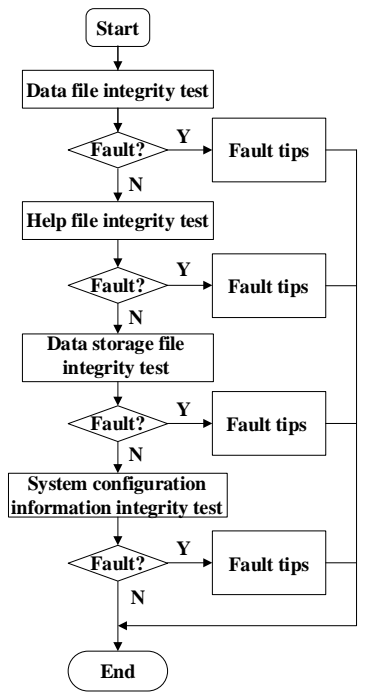

Fig 7 System software self-test flowchart

The task scheduling module is located between the data acquisition and the excitation output module and the user interface module. Its main function is to receive the task orders through the user interface, and call the underlying encapsulated collection and incentive resources to finish the job tasks.

The Database management module is mainly used to complete the storage of a variety of analog signal, discrete signal, and RS-422 data, and the working state of the specified period of time can be replayed, convenient for later analysis. 


\section{Hardware abstraction layer}

The Excitation output module mainly completes the setting of the excitation signal such as voltage signal, current signal, Ground/Open signal, 27V/Open signal and so on, and output excitation signal according to the set of quantitative. For highlevel task scheduling, the main purpose of this module is to provide a hardware-independent excitation hardware interface, with the task related hardware information maintained in this module. Excitation output module flow chart is shown in Fig 8.

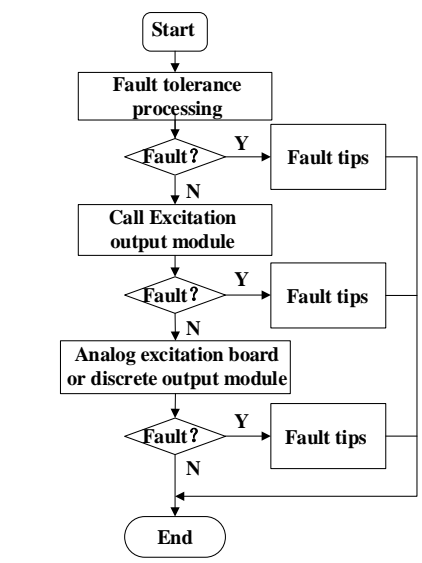

Fig 8 Excitation output module flow chart

RS-422 communication module mainly collects and analyzes the RS-422 signal sent to the RIU from each controller on the machine, and displays and stores the data according to the RIU classification. The RS-422 signals are sent to the serial server through the on-board cables, and the communication data packets are transmitted to the main control computer through the network. The main control computer parses and translates the data packets into the text, and display on the interface according to the communication protocol.

The adapter module is mainly used to control the corresponding relay to complete the configuration of analog acquisition channel, discrete variables acquisition channel, analog output channel, and discrete variables excitation output channel, according to the relationship of different RIU and the character of signal. In addition, it also can control the corresponding relay to switch the relationship among the test system, RIU, and On-board side in accordance with the test needs.

Signal acquisition module mainly completes the acquisition and storage of analog signal and discrete signal. Analog signal acquisition mainly completes the voltage, current signal acquisition. The voltage signals can be directly collected by this module. The current signals need to be converted into the corresponding voltage signal by sampling resistance, and then are acquired by this module and then are converted to the corresponding current value in the software.

Discrete variables acquisition mainly completed the acquisition of 27V/Open and Ground/Open signal. 27V/Open signal can be directly collected by this module. Ground/Open signal need to be converted to 27V/open signal through the Pull-up resistor, and then collected by this module.
The signals collected will be displayed and stored according to the RIU classification and the character of the signals. This module will call the system analog acquisition board and discrete variables acquisition card to collect continuously all the data on the specified channel with the support of the channel information, and then push data to the database management module, which will push data to the user interface for display.

\section{EXPERIMENTAL RESULTS}

Before the use of the test system, the function of each module of the system must be tested strictly. Only when the entire input and output interfaces meet the design requirements of the signal range, can the next step system alignment test be carried out.

\section{A. Frequency signal test}

The waveform of the signal outputted by analog excitation output board is $20 \mathrm{~Hz}$. The sinusoidal waveform displayed on the oscilloscope is the signal waveform detected on the specified plug pin. According to test result, the output signal is a sinusoidal waveform of $20.043 \mathrm{~Hz}$, and error accuracy is less than $0.1 \mathrm{~Hz}$, fully meeting the requirements of excitation signal. A large number of tests show that this test system can steadily acquire signals and output excitation signals, and can achieve the expected target of the test system, which also can be verified by the practical use. Frequency signal test result is shown in Fig 9.

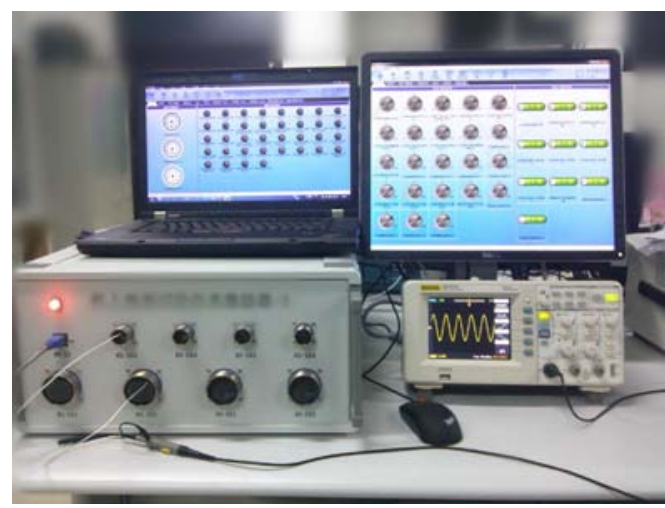

Fig 9 Physical map of the test system

\section{B. RS-422 serial communication test}

RS-422 serial communication test must be carried out under the cooperation of the external serial port server and the main control computer serial port test software. The external serial port server and the internal serial port are connected to the main control computer through the switch. The external serial port server sending interface $\mathrm{TX}+$ and the $\mathrm{TX}-$ is connected to the chassis internal serial port receiving interface $\mathrm{RX}+$ and RX-. The main control computer uses serial port test software to control external serial servers to send data. Being received by the RS-422 serial communication module of the testing system, the data packets are analyzed and compared with the data sent by the external serial port server. If consistent, the RS-422 interface works properly. Multiple different data packet samples are used in the testing process to improve the test coverage. Test results show that the test 
system software function is normal, and can meet the test requirements. RS-422 serial communication test results are shown in TABLE II .

TABLE II. RS-422 SERIAL COMMUNICATION TEST RESULTS

\begin{tabular}{|c|c|c|c|c|}
\hline No. & $\begin{array}{c}\text { Input } \\
\text { description }\end{array}$ & $\begin{array}{c}\text { Qualified } \\
\text { criterion }\end{array}$ & $\begin{array}{c}\text { Measured } \\
\text { values }\end{array}$ & Conclusion \\
\hline 1 & 0x5AA5A55A & 0x5AA5A55A & 0x5AA5A55A & Qualified \\
\hline 2 & 0x5AA5A55A & 0x5AA5A55A & $15.00349 \mathrm{~mA}$ & Qualified \\
\hline
\end{tabular}

\section{Signal acquisition test}

Signal acquisition test can be carried out with the cooperation of signal generator and multimeter or oscilloscope. The signal generator applies the specified signal to the designated aerial plug pin and then the signal in the channel will be detected by the software. In order to judge the performance of the signal acquisition, the signal detected by software will be compared with that produced by signal generator. According to test result, the system signal acquisition function can meet the demand. Signal acquisition test results are shown in TABLE III.

TABLE III. SIGNAL ACQUISITION TEST RESUlts

\begin{tabular}{|c|c|c|c|c|c|}
\hline No. & $\begin{array}{c}\text { Test } \\
\text { signal }\end{array}$ & Expectation & $\begin{array}{c}\text { Qualified } \\
\text { criterion }\end{array}$ & $\begin{array}{c}\text { Measured } \\
\text { values }\end{array}$ & Conclusion \\
\hline 1 & $\begin{array}{c}1- \\
10 \mathrm{~V}\end{array}$ & $8 \mathrm{~V}$ & $8 \pm 0.1 \mathrm{~V}$ & $8.00031 \mathrm{~V}$ & Qualified \\
\hline 2 & $\begin{array}{c}4- \\
20 \mathrm{~mA}\end{array}$ & $15 \mathrm{~mA}$ & $\begin{array}{c}15 \pm \\
0.1 \mathrm{~mA}\end{array}$ & $15.00349 \mathrm{~mA}$ & Qualified \\
\hline 3 & Open & Open & $\begin{array}{c}\text { Multimeter } \\
\text { Open }\end{array}$ & Open & Qualified \\
\hline 4 & $27 \mathrm{~V}$ & $27 \mathrm{~V}$ & $27 \pm 1 \mathrm{~V}$ & $27.00990 \mathrm{~V}$ & Qualified \\
\hline
\end{tabular}

\section{Excitation output test}

Excitation output test can be carried out with the cooperation of the system software and multimeter or oscilloscope. The system software control excitation output module to apply the specified signal to the designated aerial plug pin and then the signal in the channel will be detected by the multimeter or oscilloscope. In order to judge the performance of the signal acquisition, the signal that detected by multimeter or oscilloscope will be compared with that outputted by excitation output module. According to test result, the system excitation output function can meet the demand. Excitation output test results are shown in TABLE IV.

TABLE IV. EXCITATION OUTPUT TEST RESUlts

\begin{tabular}{|c|c|c|c|c|l|}
\hline No. & $\begin{array}{c}\text { Test } \\
\text { signal }\end{array}$ & Expectation & $\begin{array}{c}\text { Qualified } \\
\text { criterion }\end{array}$ & $\begin{array}{c}\text { Measured } \\
\text { values }\end{array}$ & Conclusion \\
\hline 1 & $1-10 \mathrm{~V}$ & $9 \mathrm{~V}$ & $9 \pm 0.1 \mathrm{~V}$ & $9.00468 \mathrm{~V}$ & Qualified \\
\hline 2 & $\begin{array}{c}4- \\
20 \mathrm{~mA}\end{array}$ & $10 \mathrm{~mA}$ & $\begin{array}{c}10 \pm \\
0.1 \mathrm{~mA}\end{array}$ & $10.00463 \mathrm{~mA}$ & Qualified \\
\hline 3 & Open & Open & $\begin{array}{c}\text { Multimeter } \\
\text { Open }\end{array}$ & Open & Qualified \\
\hline 4 & $27 \mathrm{~V}$ & $27 \mathrm{~V}$ & $27 \pm 1 \mathrm{~V}$ & $27.00756 \mathrm{~V}$ & Qualified \\
\hline
\end{tabular}

\section{CONCLUSIONS}

In this paper, this mechanical and electrical system test system has the following characteristics:

1) Signal acquisition channel and the excitation output channel are designed according to the maximum capacity of the signal in all RIU, and have a certain margin.

2) Each test case can be replaced with each other, which can enhance the reliability of the test system.

3) Signal interface and data transmission technology is mature, in line with the development trend of future testing. Especially in data transmission, the testing system has a large bandwidth margin, which can meet the needs of the future test data growth.

4) Test systems has friendly man-machine interface, stable data records, efficient data search, quick maintenance characteristics, can meet the demand of testers testing, maintenance and troubleshooting.

In this paper, this mechanical and electrical system test system, with simulation of aircraft electronic system equipment all input and output signals and analog electromechanical management computer bus communication function, can complete aircraft electrical system online state detection and functional verification. A large number of experimental tests and practical use show that the system is stable, reliable and highly portable, which can meet the requirements of comprehensive testing, and achieve the desired objectives.

\section{REFERENCES}

[1] Moir, I. Seabridge, A.G. "Management of utility systems in the experimental aircraft programme”. J. Aerospace, vol 9, pp. 28-34, 1986.

[2] Zheng Wei, Xie Xiangjun. “Advanced fighter integrated mechanical and electrical system test technology research”. J. Journal of aircraft technology, vol 36, pp. 31-35, 2010.

[3] Jiang Zhongshan, Liu Yanping, Chen Junqing. "Research on the protection of a certain type of aircraft based on MATLAB". J. Aeronautical computing technology, vol 29, pp. 51-53, 2011.

[4] Fan Jun. "Research and design of the test system of airborne electromechanical equipment” . J. Computer measurement and control, vol 27, 2013.

[5] Yang Xiaofeng, Liu Yujiao, Yao Entao. “Application of dynamic partial reconfiguration of FPGA for airborne common interface”. J. Measurement \& Control Technology, vol 31, pp. 111-113, 2012.

[6] Yu Habin, Zeng Peng, Shang Zhijun. "The management mechanism for distributed sensor network”. J. Chinese Journal of Scientific Instrument, vol 26, pp. 1203-1209, 2005.

[7] Xie Wentao. Digital Avionics (on): avionics, software and functional parts [M]. Beijing: Aviation Industry Press, .2010, 7.

[8] ARINC 664 part 7 draft 3. Avionics full duplex switched Ethernetdetermi-nistic network[S]. Annapolist: Aeronautial Radio Incorporated, 2004.

[9] Garder R. D, Andonovic I, Hunter D. K. High performance photonic avionics networking using WDM[C]. Proceedings of IEEE MILCOM 1999.1999:958-962. 